University of Wollongong

Research Online

Faculty of Social Sciences - Papers (Archive) Faculty of Arts, Social Sciences \& Humanities

2014

Changes in attitudes toward seeking mental health services: A 40-year cross-temporal meta-analysis

C Mackenzie

University of Manitoba

J Erickson

University of Manitoba

Frank Deane

University of Wollongong, fdeane@uow.edu.au

M Wright

University of Manitoba

Follow this and additional works at: https://ro.uow.edu.au/sspapers

Part of the Education Commons, and the Social and Behavioral Sciences Commons

Research Online is the open access institutional repository for the University of Wollongong. For further information contact the UOW Library: research-pubs@uow.edu.au 


\title{
Changes in attitudes toward seeking mental health services: A 40-year cross- temporal meta-analysis
}

\begin{abstract}
Although rates of treatment seeking for mental health problems are increasing, this increase is driven primarily by antidepressant medication use, and a majority of individuals with mental health problems remain untreated. Helpseeking attitudes are thought to be a key barrier to mental health service use, although little is known about whether such attitudes have changed over time. Research on this topic is mixed with respect to whether helpseeking attitudes have become more or less positive. The aim of the current study was to help clarify this issue using a cross-temporal meta-analysis of scores on Fischer and Turner's (1970) helpseeking attitude measure among university students $(N=6796)$ from 1968 to 2008. Results indicated that attitudes have become increasingly negative over time, $r(44)=-0.53, p<0.01$, with even stronger negative results when the data are weighted $(w)$ for sample size and study variance, $r(44)=$ $-0.63, p<.001$. This disconcerting finding may reflect the greater emphasis of Fischer and Turner's scale toward helpseeking for psychotherapy. Such attitudes may be increasingly negative as a result of the unintended negative effects of efforts in recent decades to reduce stigma and market biological therapies by medicalizing mental health problems.
\end{abstract}

\section{Keywords}

temporal, meta, changes, analysis, toward, seeking, mental, health, services, 40 , year, cross, attitudes

\section{Disciplines}

Education | Social and Behavioral Sciences

\section{Publication Details}

Mackenzie, C. S., Erickson, J., Deane, F. P. \& Wright, M. (2014). Changes in attitudes toward seeking mental health services: A 40-year cross-temporal meta-analysis. Clinical Psychology Review, 34 (2), 99-106. 
Running head: CHANGES IN HELP-SEEKING ATTITUDES

Changes in Attitudes toward Seeking Mental Health

Services: A 40-Year Cross-Temporal Meta-Analysis

Corey S. Mackenzie ${ }^{1}$, Julie Erickson ${ }^{1}$, Frank P. Deane ${ }^{2}$, \& Michelle Wright ${ }^{1}$

${ }^{1}$ Department of Psychology, University of Manitoba, Winnipeg, Manitoba, Canada

${ }^{2}$ School of Psychology, University of Wollongong, New South Wales, Australia

Corresponding author: $\quad$ Corey S. Mackenzie, Ph.D.

Department of Psychology

University of Manitoba

190 Dysart Rd

Winnipeg, Manitoba, Canada R3T 2N2

Email: corey.mackenzie@umanitoba.ca

Phone: (204) 474-9524 


\begin{abstract}
Although rates of treatment seeking for mental health problems are increasing, this increase is driven primarily by antidepressant medication use, and a majority of individuals with mental health problems remain untreated. Helpseeking attitudes are thought to be a key barrier to mental health service use, although little is known about whether such attitudes have changed over time. Research on this topic is mixed with respect to whether helpseeking attitudes have become more or less positive. The aim of the current study was to help clarify this issue using a cross-temporal meta-analysis of scores on Fischer and Turner's (1970) helpseeking attitude measure among university students ( $N=6,796)$ from 1968 to 2008. Results indicated that attitudes have become increasingly negative over time, $r(44)=-0.53, p<0.01$, with even stronger negative results when the data are weighted $(w)$ for sample size and study variance, $r(44)=-0.63, p<.001$. This disconcerting finding may reflect the greater emphasis of Fischer and Turner's scale toward helpseeking for psychotherapy. Such attitudes may be increasingly negative as a result of the unintended negative effects of efforts in recent decades to reduce stigma and market biological therapies by medicalizing mental health problems.
\end{abstract}

\title{
Highlights
}

- We examined changes in attitudes toward seeking mental health services over time

- Our cross-temporal meta-analysis included data from 6518 students over 40 years

- Helpseeking attitudes have become reliably more negative from 1968 to 2008

- This finding may reflect changing attitudes toward specialty mental health care

\section{Keywords}

Helpseeking Attitudes; Stigma ; Cross-Temporal Meta-Analysis; Mental Health Services 
Changes in Attitudes toward Seeking Mental Health

Services: A 40-Year Cross-Temporal Meta-Analysis

Overall rates of treatment for mental disorders in developed nations are increasing over time. Trends in outpatient treatment for depression in the USA from the Medical Expenditure Surveys indicate that in 1987 less than one person (.73) per 100 received treatment and this increased to 2.33 in 1997 (Olfson, Marcus, Druss, Elmson, Tanielian, \& Pincus, 2002), 2.37 in 1998 and 2.88 in 2007 (Marcus \& Olfson, 2010). This evidence of increasing mental health service use, however, masks different trajectories in the use of pharmacotherapy and psychotherapy. Specifically, antidepressant medication use has increased sharply since the late 1980s (Olfson et al., 2002; Pratt, Brody, \& Gu, 2011) although this trend appears to be stabilizing since the late 1990s (Marcus \& Olfson, 2010). In contrast, the proportion of people receiving outpatient psychotherapy for depression in the Medical Expenditure Surveys declined by 28\% over 20 years. Among people treated for depression, 71\% received psychotherapy in 1987, 60.2\% in 1997 (Olfson et al., 2002), 53.6\% in 1998 and 43.1\% in 2007 (Marcus \& Olfson, 2010).

Similar trends have been reported for the treatment of mental disorders in general via comparisons of the US National Comorbidity Survey (NCS), collected between 1990 and 1992, and its replication (NCS-R), collected between 2001 and 2003 (Kessler et al., 2005). Among individuals with a mood, anxiety, or substance disorder, 20.3\% received treatment in the early 1990s whereas 32.9\% received treatment in the early 2000s. By far the greatest increase in service use in these surveys occurred in the general medical sector, where treatment rates were 2.59 times as high in 2001-2003 as in 1990-1992. High rates of consultations from general 
practitioners (53\%) have also been reported in Australian samples of young people (e.g., Reavley, Yap, Wright, \& Jorm, 2011). The increase in rates of treatment over time has mostly been attributed to the expansion of psychotropic medications provided by the general medical sector.

Despite evidence of increasing rates of pharmacological treatment for mental health problems, unfortunately the majority of mental health services do not meet evidence-based guidelines, especially in the general medical sector. In the NCS minimally adequate evidence-based treatment was defined as pharmacotherapy that: lasted $\geq 2$ months, was appropriate for the focal disorder, and included $>4$ visits to any type of physician. For psychotherapy minimally adequate evidence-based treatment was defined as: $\geq 8$ visits with any health care or human services professional lasting an average of $\geq 30$ minutes. Of the treated patients in this survey with disorders, $48.3 \%$ received treatment that met minimal evidence-based standards from mental health professionals and only $12.7 \%$ received minimally adequate treatment from general medical providers (Wang et al., 2005). The authors concluded that despite increases in treatment rates over time, there remain serious problems with mental health care in the United States with use of mental health services remaining disturbingly low, most patients not receiving any care for mental disorders, and only one third of those who do seek professional help receiving treatment that meets minimal standards of adequacy.

\section{Attitudinal Barriers to Mental Health Care}

An extensive body of research has attempted to better understand barriers to mental health care. These can broadly be categorised into knowledge based, 
structural, and attitudinal ${ }^{1}$ barriers (Thompson, Hunt \& Issakidis, 2004). Examples of knowledge based barriers include not recognizing symptoms of mental disorders and not knowing where to get help. Structural barriers include financial cost, difficulty with transport and lack of available services. Attitudinal barriers include stigma related concerns, fears or embarrassment about revealing personal details, beliefs that one should handle problems by oneself, and beliefs about the probability that a service will help resolve a problem. Typically when asked, individuals describe a range of barriers to seeking help with varying degrees of influence on their help seeking (e.g., Wells, Robins, Bushnell \& Jarosz \& Oakley-Browne, 1994).

Attitudinal barriers have arguably been most consistently related to intentions to seek help and actual service utilization (e.g., Gulliver, Griffiths, \& Christensen, 2010; Jagdeo, Cox, Stein, \& Sareen, 2009; Mojtabai, Olfson, \& Mechanic, 2002; Pescosolido, Martin, Long, Medina, Phelan, \& Link, 2010; Wells, Robins, Bushnell \& Jarosz \& Oakley-Browne, 1994). Analysis of the NCS found that among those with a mental disorder and perceived need for help, the major determinants of help seeking were attitudinal and sociodemographic (Mojtabai et al., 2002). Negative attitudes toward seeking help for mental health problems are prevalent. Comparison of Canadian and US population surveys found 18\% and 24\% had negative attitudes, respectively. Rates of negative attitudes were significantly higher among younger adults aged 15 to 24, with 25\% of younger Canadians and 35\% of younger Americans holding negative attitudes toward seeking mental health services (Jagdeo et al., 2009). Some of the most frequently identified attitudinal barriers to seeking mental health care include people's wishes to handle problems on their own (Gulliver, Griffiths \& Christensen, 2010; Wells et al., 1994; Rickwood, Deane \& Wilson, 2007;

\footnotetext{
${ }^{1}$ Although Thompson and colleagues (2004) include beliefs about mental health services within their attitudinal barrier category, social psychological theory more typically views attitudes and beliefs as separate constructs.
} 
Wetherell et al., 2007, Wilson \& Deane, 2012), thinking the problem will go away by itself (Sareen, Jagdeo, Cox, Clara, ten Have, Graaf et al., 2007; Thompson et al., 2004), doubts about the perceived benefits of help seeking (e.g., ten Have et al., 2010; Rickwood et al., 2007; Rughani, Deane \& Wilson, 2011) and concerns about stigma associated with seeking mental health services (Gulliver et al., 2010; Jorm, Wright, \& Morgan, 2007; Pescosolido et al., 2010).

\section{Changing Attitudes toward People with Mental Illness}

The overwhelming evidence pointing to attitudes as a significant barrier to mental health services, has resulted in extensive efforts over the past two decades from clinicians, policy makers, and researchers to reduce negative attitudes, and in particular stigma toward mental illness. These stigma reduction efforts in the US and internationally have, in part, attempted to medicalize mental illness by focusing on its neurobiological etiology (Corrigan \& Watson, 2004; Pescosolido et al., 2010; Phelan, 2005). These efforts have also coincided with aggressive direct-to-consumer advertising of psychotropic medications that further emphasized that mental disorders are biological diseases in need of biological treatments (Rosenthal, Berndt, Donohue, Frank, \& Epstein, 2002). Unfortunately, although these attempts to educate the public and improve mental health systems have increased mental health literacy, including the endorsement of neurobiological causes and treatments of mental disorders, they have not resulted in reductions in public stigma towards people with mental illness. In fact, studies in the US (Pescosolido et al., 2010), Germany (Angermeyer, Holzinger, \& Matschinger, 2009), Turkey (Bag, Yilmaz, \& Kirpinar, 2006), Germany, Russia, and Mongolia (Dietrich, Beck, Bujantugs, Kenzine, Matschinger, \& Angermeyer, 2004) have reported that endorsements of neurobiological causes of mental illness are associated with increases in the desire for social distance from those with such 
problems. An empirically supported possible explanation for these findings (Phelan, 2005) involves perceptions of mental illnesses as having genetic causes, resulting in them being seen as more fixed, unchangeable, serious, and persistent. As a result, people with these disorders are seen as fundamentally different from those without them.

\section{Changing Attitudes Toward Seeking Mental Health Services}

Despite evidence that attitudes toward people with mental illness appear to be either stable or perhaps worsening, less is known about changes in attitudes toward seeking mental health services over time. Currin, Hayslip, and Temple (2011) surveyed perceptions of mental health and mental health services among older adults in $1977(N=90), 1991(N=101)$, and $2000(N=99)$, and among younger adults in $1991(N=131)$ and $2000(N=147)$. The authors created their own measures and administered them at all three time points, and also used Fischer and Turner's (1970) Attitudes Toward Seeking Professional Psychological Help Scale (ATSPPHS) with the 1991 and 2001 samples. This study found increasingly positive perceptions among the older sample from 1977 to 1991, whereas both the older and younger samples demonstrated significantly more negative helpseeking attitudes from 1991 to 2001 using the reliable and valid ATPSSHS.

In contrast to this evidence of worsening helpseeking attitudes in recent decades, comparison of the NCS $(\mathrm{N}=5388)$ with the NCS-R $(\mathrm{N}=4319)$ revealed that helpseeking attitudes improved over the decade between these cross-sectional surveys (Mojtabai, 2007). Three items assessed attitudes: willingness to go for professional help, comfort talking about personal problems, and embarrassment if friends knew about help seeking. The percentage reporting being at least "somewhat" embarrassed reduced from $42.5 \%$ (1990-1992) to 35.5\% (2001-2003). The 
improvement in attitudes was strongest for younger participants (18-24 years).

Similarly, participants who read vignettes about individuals with mental disorders as part of the General Social Surveys (GSS) increasingly endorsed treatment from a general medical doctor, a psychiatrist, a mental hospital, and/or prescription medications from 1996 to the 2006 survey (Pescosolido et al., 2010). The 1998 and 2006 GSS also assessed opinions about the benefits and risks of psychiatric medications and willingness to take them in hypothetical situations. Results from these surveys clearly demonstrated increasingly favorable attitudes toward drug treatment over time (Motjabai, 2009).

What might account for this conflicting evidence of worsening helpseeking attitudes in Currin and colleagues' (2011) study versus improving helpseeking attitudes in the NCS and GSS? One possible explanation may have to do with their samples; Currin and colleagues (2011) surveyed younger and older community dwelling Texans, whereas participants from the NCS and GSS were nationally representative adults. A second possible explanation is measurement reliability. Although the NCS and GSS could be considered more reliable because their large samples reduce random measurement error, the space limitations in these populationbased surveys requires very brief (between 1 and 3 items) measures of helpseeking attitudes, potentially reducing reliability. Currin and colleagues’ (2011) 1991 to 2000 comparison employed the most commonly used self-report measure of helpseeking attitudes in the literature, the 29-item ATSPPHS (Fischer \& Turner, 1970), which has proven reliability and validity. Ten Have and colleagues (2010) note that there is, "no universal standard for how attitudes toward mental health help-seeking can best be measured" (p. 160) but that research is needed to demonstrate the reliability and 
validity of brief attitude questions typically used in epidemiological population-based surveys.

A third possible explanation for the conflicting findings is that they reflected differing attitudes toward pharmacotherapy versus talk therapy. The attitude questions in the GSS referred explicitly to psychiatric medications and specific sources that typically use those pharmacological treatments (i.e., general medical doctors, psychiatrists, and mental hospitals). The attitude questions in the NCS did not refer to specific mental health providers or types of treatment, but it is likely that respondents interpreted them as referring to mental health treatment within the specialty and perhaps especially within the general medical sector, where increasing numbers of people are receiving mental health care over time (Angermeyer, Holzinger, \& Matschinger, 2009; Kessler et al., 2005). Increasing positive attitudes over time within the GSS and NCS may therefore reflect improvements in attitudes toward pharmacothearpy. In contrast, the ATSPPHS refers specifically to psychiatrists, psychologists, psychological counselling, psychotherapy, psychiatric treatment, and treatment in mental hospitals. And 14 of the 29 questions from this scale refer to talk therapy or discussing emotional difficulties. Although this scale wasn't developed as a measure of attitudes toward talk therapy, that is what it appears to predominantly measure. Increasingly negative attitudes over time on the ATSPPHS may therefore reflect worsening attitudes toward specialty mental health care in general, and/or psychotherapy more specifically. The results from two community-based surveys of public opinion of mental health service providers support this hypothesis. Angermeyer and colleagues (1999) and Jorm and colleagues (1997) both found that for depression, the public perceived psychiatrists and psychologists as being less helpful than general practitioners. 
The aim of the current study was to provide a more reliable test of whether and to what extent helpseeking attitudes, as measured by the ATSPPHS (Fischer \& Turner, 1970), have changed over time in university student populations. Analysing trends over time in attitudes toward mental health service use may help explain increasing rates of pharmacotherapy use and declining rates of psychotherapy use in the general population.

\section{Method}

\section{Literature Search and Study Inclusion}

We reviewed the literature for all published studies using the ATSPPHS (Fischer \& Turner, 1970). This 29-item scale measures four facets of help-seeking attitudes: (a) recognition of need for help (8 items, e.g., at some future time I might want to have psychological counselling), (b) tolerance for the stigma that accompanies seeking mental-health help (5 items, e.g., having been mentally ill carries with it a burden of shame), (c) interpersonal openness about psychological problems (7 items, e.g., there are experiences in my life I would not discuss with anyone), and (d) confidence in mental health professionals (9 items, e.g., although there are clinics for people with mental troubles, I would not have much faith in them). Although the ATSPPHS is a 4-factor scale, problems with its factor extraction and poor subscale reliabilities (Mackenzie, Gekoski, Knox, \& Macaulay, 2004) have lead the majority of researchers to only report its total score. Each item is rated on a scale from 0 to 3, with 11 of the 29 items reversed scored, and higher scores reflecting more positive attitudes towards seeking help.

We conducted our search using PsychINFO, PubMed, Web of Science, Google Scholar, and EBSCO for published articles and dissertations that employed the full ATSPPHS. We searched for all articles that have cited Fischer and Turner 
(1970) since its publication. We also used combinations of the following search terms to ensure that we located all articles potentially eligible for inclusion: help-seeking, attitudes, beliefs, psychological help, Fischer, Turner, counselling, therapy, and psychotherapy. Our literature search yielded 467 articles across all databases, 54\% ( $n=261$ ) of which were journal articles. For the purposes of inclusion in the current meta-analysis, studies must have used the full ATSPPHS with samples of collegeaged students in North America. We limited the sample to students both because published research employing the ATSPPHS most commonly uses them as participants, and because we required a homogenous sample so that any differences we find across time are most likely due to time rather than to differences in study samples. We restricted our sample to studies conducted in North America to minimize the influence of cross-cultural differences in attitudes toward seeking professional psychological help (Furnham \& Andrew, 1996; Sheikh \& Furnham, 2000). As a result, we excluded 137/261 articles. We also excluded studies that used clinical samples (i.e., meeting criteria for mental disorder or at risk for mental disorder) or samples with restricted sociodemographic characteristics (e.g., recent immigrants). These criteria excluded an additional 71 studies. We did not include studies that collected data on the ATSPPHS following experimental manipulations, which eliminated an additional 27 studies. Some studies collected data from multiple samples, where not all samples met our inclusion criteria. In these instances, we only used the samples within the study that met our inclusion criteria. Using the aforementioned criteria we eliminated 238/261 published articles, leaving 22 studies eligible for inclusion.

Our use of a modified meta-analysis technique called cross-temporal metaanalysis (Twenge, 2000; Twenge \& Campbell, 2001) required several pieces of 
information: total mean score and standard deviation on the measure of interest, and the year the data was collected. In instances where we could not obtain this information from the published article, we contacted study authors. We included data from authors who responded in our meta-analysis and excluded data from nonresponders, or authors who indicated that the data we requested were not available.

After restricting prior research using the ATSPPHS with our exclusion criteria we were left with 22 studies, 46 samples, and a total sample size of $n=6796$. As shown in Table 1, these studies were exclusively American, and included data collected between 1968 and 2008. For those studies for which we could not ascertain an exact year of data collection, we used the approximation of two years before publication, a previously accepted estimate (Twenge \& Campbell, 2001; Oliver \& Hyde, 1993). In addition, for those studies that did not employ a 4-point 0-3 scale, we converted their total mean scores (and if necessary, standard deviations) to the appropriate 0 to 3 scale that can range from 0 to 87 .

\section{Cross-Temporal Meta-Analysis}

Although cross-temporal meta-analysis is similar to traditional meta-analysis in that a large body of research is combined and subjected to statistical analyses to address a specific hypothesis, it differs significantly in the type of data required for analyses, the analyses conducted, and the type of conclusions drawn. In contrast to traditional meta-analyses, effect sizes are not of interest. In cross-temporal metaanalysis the primary outcome of interest is the relationship between the mean score on the outcome measure and the year these scores were collected. As such, crosstemporal meta-analysis is essentially a bivariate correlation between mean scores and years. In addition, as is typically the case in this type of meta-analysis (e.g., Twenge, 2000; Twenge \& Campbell, 2001; Twenge, Zhang, \& Im, 2004), we weighted the 
data in two ways. First, we weighted by the sample size of each study so that larger studies that provide better estimates of the population mean have a stronger influence on our findings. Second, we also report our analysis weighted by the inverse of the variance, a statistic represented by $w$, so that studies with smaller variances have a stronger influence on the final results. This technique, which is the most commonly reported weight applied in meta-analyses, includes both the sample size as well as the within-study standard deviation (i.e., within-study SD squared x $1 / n$ of the individual study), which is then inverted $(1 / v)$ to create $w$. Cross-temporal meta-analysis therefore ultimately permits a numerical index of the degree to which scores on a measure of interest have changed over time.

Thus in the present study, we ran a bivariate correlation between the total mean score on the ATSPPH and the corresponding year of data collection for each study included. In addition, we ran linear regression analyses, weighted by both $n$ and $w$, to examine the degree to which year of data collection predicted mean scores.

\section{Results}

\section{Correlation between Scores and Year}

The bivariate correlation between year of data collection and total mean ATSPPHS scores was significantly negative, $r(44)=-0.53, p<0.01$, indicating that university students' help-seeking attitudes have become significantly more negative over time. The negative relationship between time and attitude scores was very similar, and in fact even stronger, in analyses in which we weighted the data by sample size, $r(44)=-0.60$, and by $w, r(44)=-0.63$. The negative relationship between mean scores and year can also be seen via the downward sloping regression line in Figure 1, where the data are weighted by $w$.

\section{Magnitude of Change}


To further examine the magnitude of change in attitude scores, we calculated a cross-temporal effect size. We calculated the size of the decrease in scores over time using the regression equation weighted by $w$. The regression equation uses the algebraic formula $\mathrm{Y}_{\mathrm{x}}=\mathrm{Bx}+\mathrm{C}$, where $\mathrm{Y}_{\mathrm{x}}$ is the average ATSPPHS score for a particular year of interest, $\mathrm{x}$ is the year of interest, $\mathrm{B}$ is the unstandardized beta coefficient of -.23 , and c is the equation constant of 469.99. Following the procedure used by Twenge and colleagues (2004), we subtracted $\mathrm{Y}_{1968}=17.35$ from $\mathrm{Y}_{2008}=$ 8.15, yielding a difference score of $\mathrm{Y}_{2008-1968}=-9.2$. We then divided this difference by the average standard deviation $(S D=11.30)$ for all studies, to obtain $d=-.814$ for the 40 year time span that our analysis encompassed. In other words, ATSPPHS scores declined by nearly one standard deviation over the 40 -year data collection period from 1968 until 2008. We note that this procedure, which uses the standard deviation of the individual studies to capture ATSPPHS variance rather than variation in mean scores, is recommended by Twenge et. al, (2004) as a way of avoiding the ecological fallacy, which exaggerates the magnitude of the effect because mean scores do not differ as much as individual scores.

\section{Discussion}

The major finding of this review was that attitudes toward seeking psychological help have become increasingly negative, in more or less a linear manner, among American university students over the past 40 years. This finding is also consistent with evidence that public stigma about mental illness has either remained steady or worsened over time (Angermeyer, Holzinger, \& Matschinger, 2009; Pescosolido, et al., 2010).

Although rates of treatment for mental disorders have been increasing, the findings from our study may speak to why this change is largely driven by increases 
in pharmacotherapy, while at the same time we are seeing declining rates of treatment with psychotherapy (e.g., Marcus \& Olfson, 2010). We argue that the NCS and GSS helpseeking questions are primarily tapping into biological treatments from biological service providers, and those attitudes are becoming increasingly positive over time. On the other hand, nearly half of the questions on the ATSPPHS (Fischer \& Turner, 1970) refer to talk therapy or discussing mental health concerns with specialty mental health professionals, and our findings suggest that those attitudes are becoming increasingly negative over time.

It is unlikely that changes in attitudes toward pharmacotherapy versus psychotherapy is due to differences in the effectiveness of these treatments given that research suggests that talk therapy is at least as effective as drug therapy (DeRubeis, Siegle, \& Hollon, 2008). It may be that attitudes toward seeking specialty mental health care, and especially psychotherapy, are becoming increasingly negative as a result of public education and pharmacological marketing efforts to convince the public that mental disorders have a neurobiological etiology that require biological treatments such as antidepressant medications. Public education efforts have been in place since the early 1990s in the UK (Paykel, Tylee, Wright, Priest, Rix, \& Hart, 1997) and since the early 2000s in Australia, Germany (Jorm, 2012), and the United States (Pescosolido et al., 2010). In the United States recommendations were made to transform mental health care via the President's New Freedom Commission in 2003 (Hogan, 2003), which had an immediate influence on mental health organizations (Von Esenwein, Bornemann, Ellingson, Palpant, Randolph, \& Druss, 2005). Although these changes to the American mental health care system might not have occurred in time to be reflected in our data, "total spending on direct-to-consumer advertising for prescription drugs has been increasing since the early 1990s and has more than 
doubled since 1996” (Rosenthal et al., 2002, p. 502). The American public has therefore increasingly been receiving the message that mental disorders have neurobiological causes and treatments for the past two decades. Unfortunately, the focus of these marketing and educational efforts has had no effect, or perhaps a negative effect, on attitudes toward people with mental disorders (Pescosolido et al., 2010; Phelan, 2003). Our data and Currin and colleagues' (2011) suggest that it may be having a similarly negative effect on attitudes toward seeking non-biological treatments for mental disorders.

Another alternative or complementary explanation for the disconcerting findings from the current study has to do with the dynamic process of interpreting and making sense of symptoms of psychological distress that are outlined in the Cycle of Avoidance (COA) model of helpseeking (Biddle, Donovan, Sharp \& Gunnell, 2007). Essential components of the COA are the social meanings attributed to mental illness and being helped. In short, individuals with mental health problems try to avoid accepting that they have "real distress" by repeatedly negotiating new meaning to symptoms and normalizing their experiences. This results in a moving threshold for defining their need for help. In addition, the social meaning attached to receiving help (e.g., stigma) is generally negative and this further drives the avoidance cycle. The COA is considered a "dynamic" model but it has the potential to help understand key factors that might be driving the presence of negative attitudes toward professional psychological help over time. Although efforts to conceptualize mental disorders as biological diseases may go some way to explaining negative attitudes toward seeking specialty mental health services, it is also possible that, over time, we have developed a greater tolerance or "acceptance" of higher levels of distress as a normal part of life. 
If this were the case then the COA model of failure to seek help would suggest that the distress and attitudinal threshold for accepting help would also go up.

It is unclear whether as a society tolerance or acceptance of stress and distress in day-to-day life are increasing. However, reliable evidence exists to suggest that levels of stress and psychological distress are increasing over time in Western nations. In three US national surveys conducted in 1983, 2006 and 2009 perceived stress reliably increased from the 1980s to the mid to late 2000s in adults under the age of 65 (Cohen \& Janicki-Deverts, 2012). Among American college students, crosstemporal meta-analyses have demonstrated substantial increases of about one standard deviation in anxiety since the 1950s (Twenge, 2000) and psychopathology since the 1930s (Twenge et al., 2010). Finally, data from two large (Ns exceeding 42,000) nationally representative surveys conducted in 1991-1992 to 2001-2002 demonstrated that the prevalence of major depression increased from 3.33\% to $7.06 \%$ for all age groups (Compton, Conway, Stinson, \& Grant, 2006).

Regardless of the reasons for increasingly negative attitudes toward specialty mental health services over time, the finding is concerning because mental health services continue to be underutilized despite the fact that clinicians, policy makers, and researchers have been concerned about low rates of professional mental health service use for three decades. While negative attitudes toward seeking help almost certainly contribute to this ongoing problem, efforts to reduce stigma and improve helpseeking attitudes have not always been effective (de Man, Fauteux \& McKelvie, 2008; Eisenberg et al., 2012), have only rarely had long term follow-up (Dalky, 2012), and when there is longer term follow-up positive effects usually decline (e.g., Finkelstein, Lapshin \& Wasserman, 2008). Further, effective interventions have not 
translated into improvements in actual helpseeking (Jorm, Griffiths, Christensen, Korten, Parslow, \& Rogers, 2003).

\section{Strengths and Limitations.}

The strength of this study was its use of a standardized, reliable, and well validated multi-item self report helpseeking attitude measure that has a focus on professional sources of help for mental health problems. The primary finding from this study was also reliable, in that it was unaffected by sample size or outcome measure variance of individual studies. Despite these strengths, the results of this study need to be considered in the context of several limitations. First, some studies had relatively small sample sizes and provided minimal detail about their sampling methods. Second, for logistic reasons this study only included university undergraduate students and we had insufficient data to analyze for gender effects despite the fact that helpseeking attitudes are affected by age and gender (e.g., Mackenzie, Gekoski, \& Knox, 2006). As a result our findings may not generalize to other sociodemographic groups and care should be taken when comparing our findings to those from other populations and nationally representative samples. Third, the ATSPPHS (Fischer \& Turner, 1970) refers to specialty mental health care professionals and treatments, and does therefore not allow an assessment of attitudes toward seeking mental health care in the primary medical sector. Future research should consider measuring attitudes toward seeking mental health care within the specialty versus general medical sectors, and also explicitly assessing attitudes toward seeking psychotherapy versus pharmacotherapy. Assessing changes in such attitudes over time will be important given the results of the current study.

\section{Conclusion}


Countries throughout the developing world have both recognized problems with mental health care and taken action in an attempt to help individuals who need such care (Hogan, 2003; Jorm, 2012; Mental Health Commission of Canada, 2005; Paykel et al., 1997; Pescosolido et al., 2010). The results of this study provide further evidence in support of the importance of such efforts, although they also suggest that at least some of these efforts may not be having the intended effects, at least in terms of improving attitudes toward seeking specialty mental health care. Given reliable evidence of increasing prevalence of mental health problems over time (e.g., Compton et al., 2006) and a majority of individuals with mental disorders still not accessing professional help (e.g., Wang et al., 2005), we must continue to develop our understanding of helpseeking attitudes and other barriers to seeking help in order to improve access to professional treatment. Our mental health systems and those they serve depend on this information.

\section{Acknowledgements}

This work was supported by a Manitoba Health Research Council (MHRC) Establishment Grant to CSM. 


\section{References}

Angermeyer, M. C., Holzinger, A., \& Matschinger, H. (2009). Mental health literacy and attitude towards people with mental illness: A trend analysis based on population surveys in the eastern part of Germany. European Psychiatry, 24, 225-232.

Angermeyer, M. C., Matschinger, H., \& Riedel-Heller, S. (1999). Whom to ask for help in the case of a mental disorder: Preferences of the lay public. Social Psychiatry and Psychiatric Epidemiology, 34, 202-210.

Bag, B., Yilmaz, S., \& Kirpinar, I. (2006). Factors influencing social distance from people with schizophrenia. International Journal of Clinical Practice, 60(3), 289-294.

Biddle, L., Donovan, J., Sharp, D., \& Gunnell, D. (2007). Explaining non-helpseeking amongst young adults with mental distress: A dynamic interpretive model of illness behaviour. Sociology of Health and Illness, 29(7), 983-1002.

*Blazina, C., \& Marks, L. (2001). College men's affective reactions to individual therapy, psychoeducational workshops, and men's support group brochures: The influence of gender-role conflict and power dynamics upon help-seeking attitudes. Psychotherapy: Theory, Research, Practice, Training, 38(3), 297-305.

*Brody, S. (1994). Traditional ideology, stress, and psychotherapy use. Journal of Psychology: Interdisciplinary and Applied, 128(1), 5-13.

*Cash, T., Kehr, J., \& Salzbach, R. (1978). Help-seeking attitudes and perceptions of counselor behavior. Journal of Counseling Psychology, 25(4), 264-269.

Centers for Disease Control and Prevention (1999). Ten great public health achievements: United States, 1990-1999. MMWR Morbidity Mortality Weekly Report, 48(12), 241-243. 
Centers for Disease Control and Prevention (2011). Ten great public health achievements: Worldwide, 2001-2010. MMWR Morbidity Mortality Weekly Report, 60(24), 814-818.

*Cepeda-Benito, A., \& Short, P. (1998). Self-concealment, avoidance of psychological services, and perceived likelihood of seeking professional help. Journal of Counseling Psychology, 45(1), 58-64.

Cohen, S., \& Janicki-Deverts, D. (2012). Who's stressed? Distributions of psychological stress in the United States in probability samples from 1983, 2006, and 2009. Journal of Applied Social Psychology, 42(6), 1320-1334.

Compton, W. M., Conway, K., Stinson, F., \& Grant, B. (2006). Changes in the prevalence of major depression and comorbid substance use disorders in the United States between 1991-1992 and 2001-2002. The American Journal of Psychiatry, 163(12), 2141-2147.

Corrigan, P. W., \& Watson, A. C. (2004). At issue: Stop the stigma: Call mental illness a brain disease. Schizophrenia Bulletin, 30, 477-479.

*Currin, J. B., Hayslip Jr., B., \& Temple, J. R. (2011). The relationship between age, gender, historical change, and adults' perceptions of mental health and mental health services. International Journal of Aging and Human Development, 72(4), 317-341.

Dalky, H. F. (2012). Mental illness stigma reduction interventions: Review of intervention trials. Western Journal of Nursing Research, 34(4), 520-547.

DeRubeis, R. J., Siegle, G. J., \& Hollon, S. D. (2008). Cognitive therapy vs. medications for depression: Treatment outcomes and neural mechanisms. Nature Review Neuroscience, 9(10), 788-796. 
de Man, A. F., Fauteux, D. J., \& McKelvie, S. J. (2008). Effects of exposure to public figures' use of psychologists on attitude towards help-seeking behavior. North American Journal of Psychology, 10(2), 385.

Eisenberg, D., Downs, M. F., \& Golberstein, E. (2012). Effects of contact with treatment users on mental illness stigma: Evidence from university roommate assignments. Social Science \& Medicine, 75, 1122-1127.

*Ey, S., Henning, K., \& Shaw, D. (2000). Attitudes and factors related to seeking mental health treatment among medical and dental students. Journal of College Student Psychotherapy, 41(3), 23-39.

Finkelstein, J., Lapshin, O., \& Wasserman, E. (2008). Randomised study of different anti-stigma media. Patient Education and Counseling, 71, 204-214.

*Fischer, E., \& Cohen, S. (1972). Demographic correlates of attitude toward seeking professional psychological help. Journal of Consulting and Clinical Psychology, 39(1), 70-74.

*Fischer, E. H., \& Turner, J. L. (1970). Orientations to seeking professional healp. Development and research utility of an attitude scale. Journal of Consulting and Clinical Psychology, 35, 79-90.

Furnham, A., \& Andrew, R. A cross-cultural study of attitudes towards seeking psychological help. Psychological Reports, 79, 289-290.

*Good, G. E., Dell, D. M., \& Mintz, L. B. (1989). Male role and gender role conflict: Relations to help seeking in men. Journal of Counseling Psychology, 36(3), 295-300.

Gulliver, A., Griffiths, K. M., \& Christensen, H. (2010). Perceived barriers and facilitators to mental health help-seeking in young people: A systematic review. BMC Psychiatry, 10, 113. 
Hogan, M. F. (2003). The President's New Freedom Commission: Recommendations to transform mental health care in America. Psychiatric Services, 54(11), 14671474.

Jagdeo, A., Cox, B. J., Stein, M. B., \& Sareen, J. (2009). Negative attitudes toward help seeking for mental illness in 2 population-based surveys from the United States and Canada. Canadian Journal of Psychiatry, 54, 757-766.

Jorm, A. F. (2012). Mental health literacy: Empowering the community to take action for better mental health. American Psychologist, 3, 231-243.

Jorm, A. F., Christensen, H., \& Griffiths, K.M. (2006). The public's ability to recognize mental disorders and their beliefs about treatment: changes in Australia over 8 years. Australian and New Zealand Journal of Psychiatry, 40, $36-41$.

Jorm, A. F., Korten, A. E., Jacomb, P. A., Christensen, H., Rogers, B. \& Pollitt, P. (1997). 'Mental health literacy': A survey of the public's ability to recognize mental disorders and their beliefs about the effectiveness of treatment. Medical Journal of Australia, 166, 182-186.

Jorm, A. F., Griffiths, K. M., Christensen, H., Korten, A. E., Parslow, R. A., \& Rodgers, B. (2003). Providing information about the effectiveness of treatment options to depressed people in the community: A randomized controlled trial of effects of mental health literacy, help-seeking and symptoms. Psychological Medicine, 33, 1071-1079.

Jorm, A. F., Wright, A., \& Morgan, A. J. (2007). Where to seek help for a mental disorder? National survey of the beliefs of Australian youth and their parents. Medical Journal of Australia., 187, 556-560. 
*Kelly, A., \& Achter, J. (1995) Self-concealment and attitudes toward counselling in university students. Journal of Counseling Psychology, 42(1), 40-46.

Kessler, R. C., Demler, O., Frank R. G., Olfson, M. Pincus, H. A., Walters, E. E., Wang, P., Wells, K. B., \& Zaslavsky, A. M. (2005). Prevalence and treatment of mental disorders 1990 to 2003. New England Journal of Medicine, 352, 25152523.

*Leong, F., \& Zachar, P. (1999). Gender and opinions about mental illness as predictors of attitudes toward seeking professional psychological help. British Journal of Guidance and Counselling, 27(1), 123-132.

*Liao, H.-S., Rounds, J., \& Klein, A. (2005). A Test of Cramer's (1999) help-seeking model and acculturation effects with Asian and Asian American College Students. Journal of Counseling Psychology, 52(3), 400-411.

Mackenzie, C. S., Gekoski, W. L., \& Knox, V. J. (2006). Age, gender, and the underutilization of mental health services: The influence of helpseeking attitudes. Aging and Mental Health, 10, 574-582.

Mackenzie, C. S., Knox, V. J., Gekoski, W. L., and Macaulay, H. L. (2004). An adaptation and extension of the Attitudes Toward Seeking Professional Psychological Help Scale. Journal of Applied Social Psychology, 34, 24102435.

*Mansfield, A., Addis, M., \& Courtenay, W. (2005). Measurement of men's help seeking: development and evaluation of the Barriers to Help Seeking Scale. Psychology of Men and Masculinity, 6(2), 95-108.

Marcus, S. C., \& Olfson, M. (2010). National trends in the treatment for depression from 1998 to 2007. Archives in General Psychiatry, 67, 1265-1273. 
*Masuda, A., Suzumura, K., Beauchamp, K., Howells, G., \& Clay, C. (2005). United States and Japanese college students' attitudes toward seeking professional psychological help. International Journal of Psychology 40(5), 303-313.

*Masuda, A., Anderson, P., Twohig, M., Feinstein, A., Chou, Y-Y, Wendel, J., \& Stormo, A. (2009). Help-seeking experiences and attitudes among African American, Asian American, and European American college students. International Journal for the Advancement of Counselling, 31(3), 168-180.

Mental Health Commission of Canada. http://www.mentalhealthcommission.ca/. 2005; Accessed January 14, 2013.

Mojtabai, R. (2007). Americans' attitudes toward mental health treatment seeking: 1990-2003. Psychiatric Services, 58, 642-651.

Mojtabai, R. (2009). Americans' attitudes toward psychiatric medications: 1998-2006. Psychiatric Services, 60, 1015-1023.

Mojtabai, R., Olfson, M., \& Mechanic, D. (2002). Perceived need and help-seeking in adults with mood, anxiety, or substance use disorders. Archives of General Psychiatry, 59, 77-84.

Olfson, M., Marcus, S. C., Druss, B., Elinson, L., Tanielian, T., \& Pincus, H. A. (2002). National trends in the outpatient treatment of depression. Journal of the American Medical Association, 287(2), 203-209.

Oliver, M.B., \& Hyde, J.S., (1993). Gender differences in sexuality: A meta-analysis. Psychological Bulletin, 114(1), 29-51.

Pescosolido, B. A., Martin, J. K., Long,, J. S., Medina, T. R., Phelan, J. C., \& Link, B. G. (2010). "A disease like any other?” A decade of change in public reactions to schizophrenia, depression, and alcohol dependence. American Journal of Psychiatry, 167, 1321-1330. 
Phelan, J. C. (2005). Geneticization of deviant behavior and consequences for stigma: The case of mental illness. Journal of Health and Social Behavior, 46, 307-322.

Reavley, N. J., Yap, M. B. H., Wright, A., \& Jorm, A. F. (2011). Actions taken by young people to deal with mental disorders: Findings from an Australian national survey of youth. Early Intervention in Psychiatry, 5, 335-342.

Rickwood, D., Deane, F. P., \& Wilson, C. (2007). When and how do young people seek professional help for mental health problems? Medical Journal of Australia, 187, S35-S39.

Rosenthal, M. B., Berndt, E. R., Donohue, J. M., Frank, R. G., \& Epstein, A. M. (2002). Promotion of prescription drugs to consumers. New England Journal of Medicine, 346, 498-505.

Rughani, J., Deane, F. P., \& Wilson, C. J. (2011). Rural adolescents' help-seeking intentions for emotional problems: The influence of perceived benefits and stoicism. Australian Journal of Rural Health, 19, 64-69.

Sareen, J., Jagdeo, A., Cox, B.J., Clara, I., ten Have, M., Belik, S., de Graaf, R., et al. (2007). Perceived barriers to mental health service utilization in the United States, Ontario, and the Netherlands. Psychiatric Services, 58, 357-364.

Sheikh, S., \& Furnham, A. A cross-cultural study of mental health beliefs and attitudes towards seeking professional help. Social Psychiatry and Psychiatric Epidemiology, 35, 326-334.

ten Have, M., de Graaf, R., Ormel, J., Vilagut, G., Kovess, V., Alonso, J., \& the ESEMeD/MHEDEA 2000 investigators. (2010). Are attitudes towards mental health help-seeking associated with service use? Results from the European Study of Epidemiology of Mental Disorders. Social Psychiatry and Epidemiology, 45, 153-163. 
Thompson, A., Hunt, C., \& Issakidis, C. (2004). Why wait? Reasons for delay and prompts to seek help for mental health problems in an Australian clinical sample. Social Psychiatry and Psychiatric Epidemiology, 39, 810-817.

*Tokar, D., Fischer, A., Schaub, M., \& Moradi, B. (2000). Masculine gender roles and counseling-related variables: Links with and mediation by personality. Journal of Counseling Psychology, 47(3), 380-393.

Twenge, J. M. (2000). The age of anxiety? Birth cohort change in anxiety and neuroticism, 1952-1993. Journal of Personality and Social Psychology, 79, 1007-1021.

Twenge, J. M., \& Campbell, W. K., (2001). Age and birth cohort differences in selfesteem: A cross-temporal meta-analysis. Personality and Social Psychology Review, 5(4), 321-344.

Twenge, J. M., Gentile, B., DeWall, C. N., Ma, D., Lacefield, K., \& Schurtz, D. R. (2010). Birth cohort increases in psychopathology among young Americans, 1938-2007. Clinical Psychology Review, 30, 145-154.

Twenge, J. M., Zhang, L., \& Im, C. (2004). It's beyond my control: A cross-temporal meta-analysis of increasing externality in locus of control, 1960-2002. Personality and Social Psychology Review, 8(3), 308-319.

*Uffelman, R., \& Hardin, S. (2002). Session limits at university counseling centers: Effects on help-seeking attitudes. Journal of Counseling Psychology, 49(1), 127-132.

*Vogel, D., \& Wester, S. (2003). To seek help or not to seek help: The risks of selfdisclosure. Journal of Counseling Psychology, 50(3), 351-361.

von Esenwein, S. A., Bornnemann, T., Ellingson, L., Palpant, R., Randolph, L., \& Druss, B. G. (2005). A survey of mental health leaders one year after the 
President's New Freedom Commission Report. Psychiatric Services, 56, 605607.

Wang, P. S., Lane, M., Olfson, M., Pincus, H. A., Wells, K. B., \& Kessler, R. C. (2005). Twelve-month use of mental health services in the United States: Results from the National Comorbidity Survey Replication. Archives of General Psychiatry, 62, 629-640.

*Watson, J. (2005). College student-athletes' attitudes toward help-seeking behaviour and expectations of counseling services. Journal of College Student Development, 46(4), 442-449.

Wells, J. E., Robins, L. N., Bushnell, J. A., Jarosz, D., \& Oakley-Browne, M. A. (1994). Perceived barriers to care in St.Louis (USA) and Christchurch (NS): Reasons for not seeking professional help for psychological distress. Social Psychiatry and Psychiatric Epidemiology, 29, 155-164.

Wilson, C. J., \& Deane, F. P. (2012). Brief Report: Need for autonomy and other perceived barriers relating to adolescents' intentions to seek professional mental health care. Journal of Adolescence, 35, 233-237.

*Wisch, A., Mahalik, J., Hayes, J., \& Nutt, E. (1995). The impact of gender role conflict and counseling technique on psychological help-seeking in men. Sex Roles, 33(1-2), 77-89.

*Wolkon, G., Moriwaki, S., \& Williams, K. (1973). Race and social class as factors in the orientation toward psychotherapy. Journal of Counseling, 20(4), 312-316.

*Zeldow, P., \& Greenberg, R. (1979). Attitudes toward women and orientation to seeking professional psychological help. Journal of Clinical Psychology, 35(2), 473-476. 
*Indicates studies included in the meta-analysis 
Appendix A

Cross-Temporal Meta-Analysis References Not Cited in Text

Blazina \& Marks (2001)

Brody (1994)

Cash, Kehr \& Salzbach (1978)

Cepeda-Benito \& Short (1998)

Good, Dell \& Mintz (1989)

Kelly \& Achter (1995)

Leong \& Zachar (1999)

Liao, Rounds \& Klein (2005).

Mansfield, Addis \& Courtenay (2005)

Masuda et al., (2005)

Masuda et al., (2009).

Tokar, Fischer, Schaub \& Moradi (2000)

Uffelman \& Hardin (2002)

Vogel \& Wester (2003)

Watson (2005)

Wisch, Mahalik, Hayes, \& Nutt (1995).

Wolkon, Moriwaki \& Williams (1973).

Zeldow \& Greenberg (1979) 


\section{Figure Caption}

Figure 1. Correlation between college students' helpseeking attitude total scores and year of data collection, weighted by $w$. 
Table 1. Information for Studies Included in the Cross-Temporal Meta-Analysis

\begin{tabular}{|c|c|c|c|c|c|c|}
\hline $\begin{array}{c}\text { Study Authors, Publication Date, } \\
\text { and Subsamples }\end{array}$ & $\begin{array}{c}\text { Year of } \\
\text { Data } \\
\text { Collection }\end{array}$ & $\mathrm{N}$ & $\begin{array}{l}\text { Total } \\
\text { Score } \\
\text { Mean }\end{array}$ & $\begin{array}{c}\text { Total } \\
\text { Score } \\
\text { SD }\end{array}$ & $\mathrm{W}$ & Sex \\
\hline Blazina \& Marks (2001) & 1999 & 107 & 46.45 & 10.57 & 0.95 & M \\
\hline Brody (1994) & 1982 & 150 & 54.98 & 9.75 & 1.58 & $\mathrm{M} / \mathrm{F}$ \\
\hline Cash, Kehr \& Salzbach (1978) 1a & 1977 & 31 & 61.4 & 9.6 & 0.34 & $\mathrm{~F}$ \\
\hline $1 \mathrm{~b}$ & 1977 & 188 & 54.3 & 9.8 & 1.96 & \\
\hline Cepeda-Benito \& Short (1998) & 1996 & 732 & 49.27 & 11.72 & 5.33 & $\mathrm{M} / \mathrm{F}$ \\
\hline $\begin{array}{l}\text { Currin, Hayslip \& Temple, (2011) } \\
\text { 1a }\end{array}$ & 1991 & 131 & 54.98 & 11.35 & 1.02 & $\mathrm{M} / \mathrm{F}$ \\
\hline $1 \mathrm{~b}$ & 2000 & 147 & 51.31 & 11.1 & 1.19 & $1 \mathrm{~b}$ \\
\hline Ey, Henning \& Shaw (2000) 1a & 1996 & 65 & 49.73 & 11.17 & 0.52 & $\mathrm{M} / \mathrm{F}$ \\
\hline $1 \mathrm{~b}$ & 1996 & 226 & 55.71 & 12.67 & 1.41 & \\
\hline $1 \mathrm{c}$ & 1996 & 24 & 65.2 & 9.03 & 0.29 & \\
\hline Fischer \& Cohen (1972) 1a & 1968 & 587 & 57.5 & 12 & 4.08 & $\mathrm{M} / \mathrm{F}$ \\
\hline $1 \mathrm{~b}$ & 1968 & 263 & 59.9 & 11.4 & 2.02 & \\
\hline Fischer \& Turner (1970) 1a & 1968 & 227 & 63.2 & 11.4 & 1.75 & $\mathrm{M} / \mathrm{F}$ \\
\hline $1 \mathrm{~b}$ & 1968 & 231 & 56.1 & 11.8 & 1.66 & \\
\hline $1 \mathrm{c}$ & 1968 & 166 & 56.5 & 10.8 & 1.42 & \\
\hline $1 d$ & 1968 & 113 & 58.2 & 10.5 & 1.02 & \\
\hline Good, Dell \& Mintz (1989) & 1986 & 401 & 45.14 & 11.59 & 2.98 & $\mathrm{M}$ \\
\hline Kelly \& Achter (1995)1a & 1993 & 22 & 52.82 & 14.2 & 0.11 & $\mathrm{M} / \mathrm{F}$ \\
\hline $1 \mathrm{~b}$ & 1993 & 21 & 55.86 & 12.11 & 0.14 & \\
\hline Leong \& Zachar (1999) 1a & 1990 & 153 & 46.8 & 12.7 & 0.95 & $\mathrm{M} / \mathrm{F}$ \\
\hline $1 \mathrm{~b}$ & 1990 & 136 & 53.4 & 12 & 0.94 & \\
\hline Liao, Rounds \& Klein (2005) & 2000 & 537 & 50.02 & 15.06 & 2.37 & $\mathrm{M} / \mathrm{F}$ \\
\hline $\begin{array}{l}\text { Mansfield, Addis \& Courtenay } \\
\text { (2005) }\end{array}$ & 2003 & 58 & 59.98 & 9.28 & 0.67 & $\mathrm{M}$ \\
\hline Masuda et al. (2009) & 2008 & 518 & 52.41 & 13.18 & 2.98 & $\mathrm{M} / \mathrm{F}$ \\
\hline Masuda et al. (2005) 1a & 1998 & 103 & 46.4 & 12.7 & 0.64 & $\mathrm{M} / \mathrm{F}$ \\
\hline $1 \mathrm{~b}$ & 1998 & 197 & 54.8 & 11.6 & 1.46 & \\
\hline $\begin{array}{l}\text { Tokar, Fischer, Schaub \& Moradi } \\
(2000)\end{array}$ & 1997 & 173 & 49.3 & 12.18 & 1.16 & $\mathrm{M}$ \\
\hline Uffelman \& Hardin (2002) & 1999 & 300 & 50.97 & 11.12 & 2.42 & $\mathrm{M} / \mathrm{F}$ \\
\hline Vogel \& Wester (2003) & 2003 & 209 & 55.1 & 13 & 1.23 & $\mathrm{M} / \mathrm{F}$ \\
\hline Watson (2005) 1a & 2002 & 135 & 44.84 & 7.67 & 2.29 & $\mathrm{M} / \mathrm{F}$ \\
\hline $1 \mathrm{~b}$ & 2002 & 132 & 47.15 & 7.38 & 2.42 & \\
\hline $\begin{array}{l}\text { Wisch, Mahalik, Hayes, \& Nutt } \\
\text { (1995) 1a }\end{array}$ & 1993 & 51 & 54.8 & 12 & 0.35 & $\mathrm{M}$ \\
\hline $1 \mathrm{~b}$ & 1993 & 38 & 53.1 & 15.2 & 0.16 & \\
\hline
\end{tabular}




\begin{tabular}{|l|l|l|l|l|l|l|}
\hline 1c & 1993 & 33 & 43.4 & 10.4 & 0.31 & \\
\hline 1d & 1993 & 42 & 52 & 15.2 & 0.18 & \\
\hline $\begin{array}{l}\text { Wolkon, Moriwaki \& Williams } \\
(1973) \text { 1a }\end{array}$ & 1972 & 20 & 60.05 & 11.77 & 0.14 & F \\
\hline 1b & 1972 & 25 & 61.04 & 8.3 & 0.36 & \\
\hline 1c & 1972 & 24 & 52.25 & 13.19 & 0.14 & \\
\hline Zeldow \& Greenberg (1979) 1a & 1977 & 8 & 63.25 & 7.41 & 0.15 & M/F \\
\hline 1b & 1977 & 12 & 57.67 & 11.63 & 0.09 & \\
\hline $1 \mathrm{c}$ & 1977 & 12 & 62.83 & 10.84 & 0.10 & \\
\hline $1 \mathrm{~d}$ & 1977 & 8 & 63.38 & 9.11 & 0.10 & \\
\hline $1 \mathrm{e}$ & 1977 & 6 & 55.67 & 7.68 & 0.10 & \\
\hline $1 \mathrm{f}$ & 1977 & 14 & 51.14 & 12.74 & 0.09 & \\
\hline $1 \mathrm{~g}$ & 1977 & 4 & 61.25 & 11.44 & 0.03 & \\
\hline 1h & 1977 & 16 & 50.56 & 12.26 & 0.11 & \\
\hline
\end{tabular}




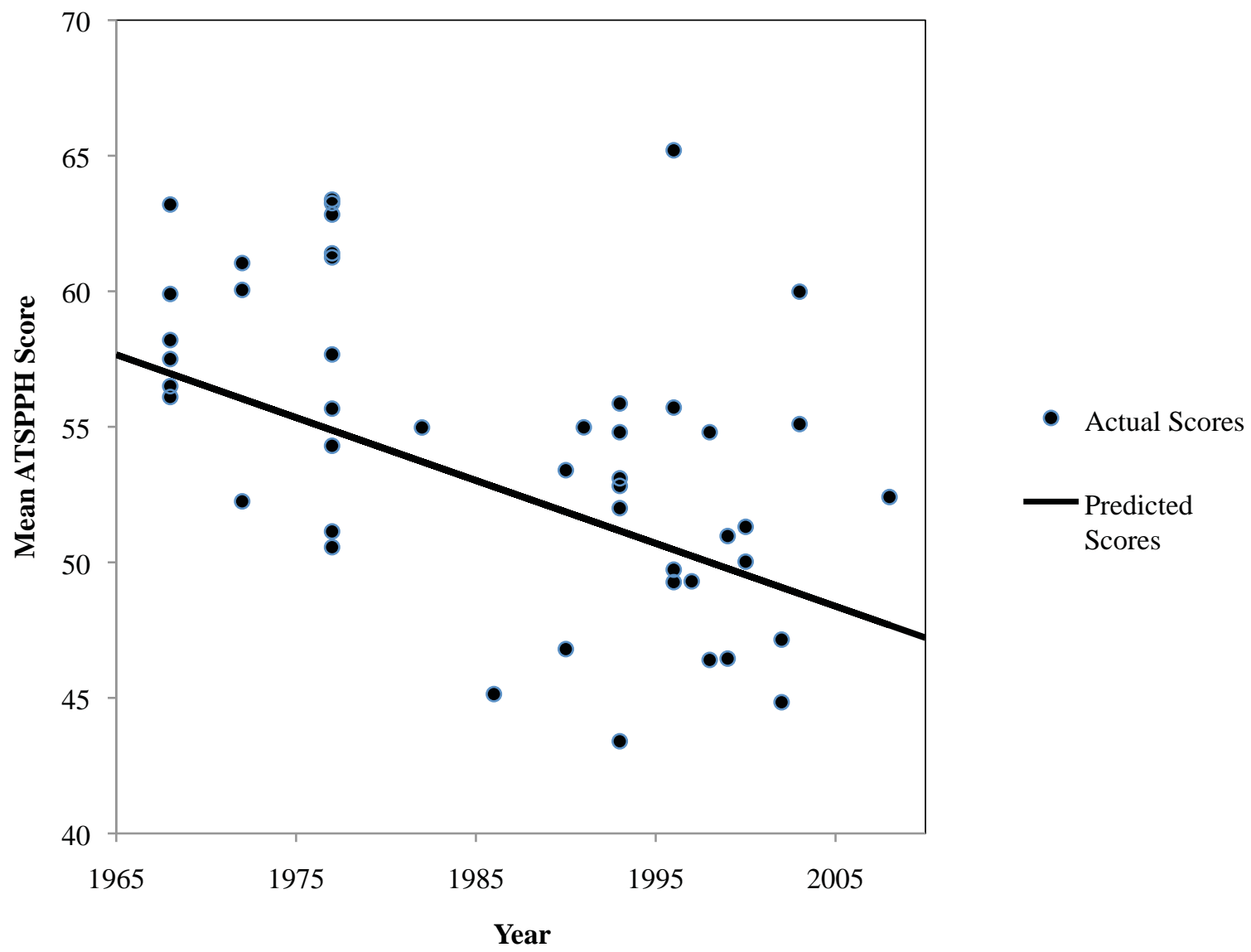

Figure 1. Correlation between college students' helpseeking attitude total scores and year of data collection, weighted by $w$. 